\title{
Adult rectosigmoid junction intussusception presenting with rectal prolapse
}

Jing Zeng $\underline{D u}^{1}$, MBBS, Li Tserng $\underline{T e O}^{1}$, FRCSE, FAMS, Ming Terk $\underline{\text { Chiu }}{ }^{1}$, FRCS, FAMS

\begin{abstract}
Most cases of intussusception in adults present with chronic and nonspecific symptoms, and can sometimes be challenging to diagnose. We herein report on a patient with the rare symptom of colonic intussusceptions presenting with rectal prolapse and review the existing literature of similar case reports to discuss how to reach an accurate diagnosis. A 75-year-old woman with dementia presented with per rectal bleeding, rectal prolapse and lower abdominal pain. An operation was scheduled and a large sigmoid intussusception with a polyp as a leading point was found intraoperatively. She subsequently recovered well and was discharged. As large sigmoid intussusceptions may present as rectal prolapse, intussusception should be considered as a differential diagnosis for immobile patients, especially when the leading point is a lesion.
\end{abstract}

Keywords: diagnosis, intussusception, rectal prolapse, treatment

\section{INTRODUCTION}

Symptoms of intussusception in adults are not as typical as those in paediatric cases. Most adult cases present with chronic and nonspecific symptoms such as nausea, vomiting, gastrointestinal bleeding, constipation and abdominal distention. ${ }^{(1)}$ Thus, they can sometimes be challenging to diagnose. We herein present an even rarer presentation of intussusceptions: rectal prolapse. We review the literature of similar case reports in which intussusception presents with rectal prolapse and discuss ways to reach an accurate diagnosis.

\section{CASE REPORT}

A 75-year-old Chinese woman was bedridden and uncommunicative due to a previous femoral neck fracture and dementia. She presented with per rectal (PR) bleeding for five days and lower abdominal pain for a day, according to the medical history provided by her family. On admission, the patient was clinically stable (temperature $37.3^{\circ} \mathrm{C}$, blood pressure 135/90 mmHg, heart rate 94 bpm). A physical examination revealed that her abdomen was soft and non-distended. There was tenderness at the lower abdomen with no rebound tenderness. A rectal examination revealed a 'prolapsed rectum' of about $4 \mathrm{~cm}$, with a $2 \mathrm{~cm} \times 1 \mathrm{~cm}$ broad-based polyp at the leading point and bleeding from the polyp (Fig. 1). The mucosa appeared healthy. Manual reduction was attempted but was unsuccessful, as prolapse recurred spontaneously after the reduction. The patient's blood tests showed that her total white blood cell count was slightly raised and kidney function was normal. An abdominal radiograph showed faecal loading without signs of obstruction (Fig. 2). The clinical impression was that of a rectal prolapse with a lead point due to a rectal polyp. An elective operation for the rectal prolapse was scheduled, as the patient had multiple morbidities and was on warfarin for a recent pulmonary embolism.

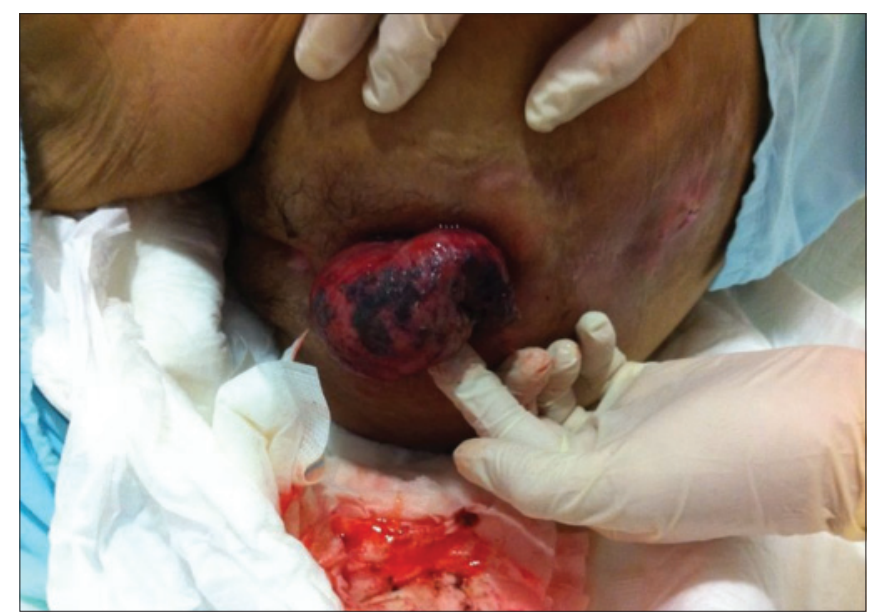

Fig. 1 Photograph shows rectal prolapse with broad-based polyp at the leading point.

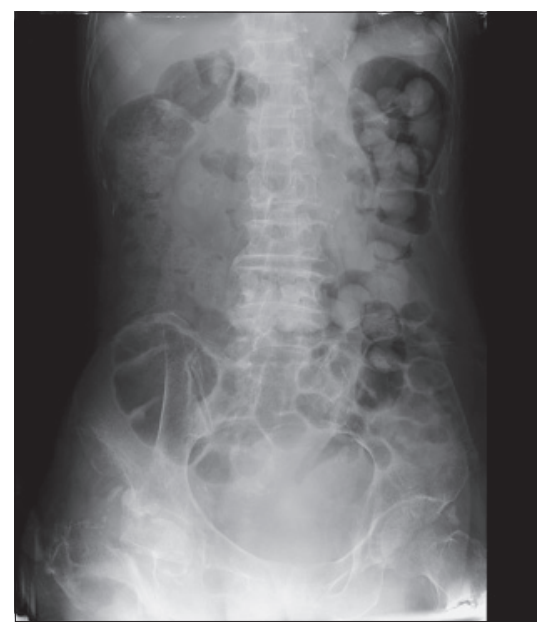

Fig. 2 Abdominal radiograph taken on arrival shows faecal loading but no sign of obstruction. 

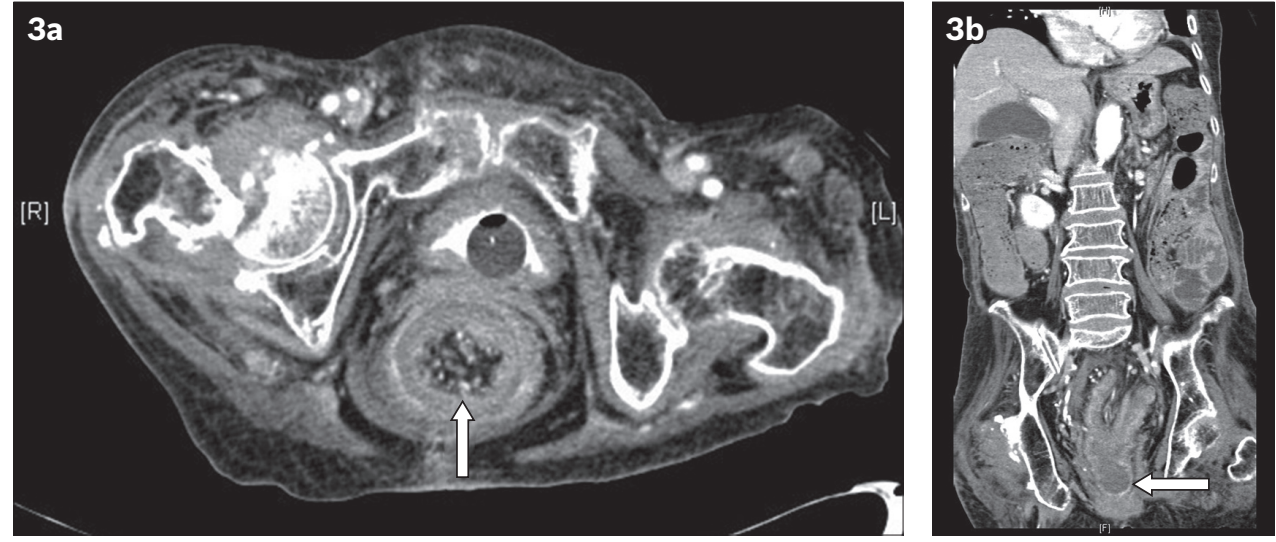

Fig. 3 CT images of the (a) abdomen and (b) pelvis show sigmoid colon intussusception (arrows).

A sigmoidoscopy was subsequently performed on Day 2 of admission. During the procedure, we inserted the sigmoidoscope to $25 \mathrm{~cm}$ and found a large rectal prolapse with a polyp as the lead point, with no obvious intussusception. Biopsies of the polyp were taken. However, the procedure was aborted after insertion to $25 \mathrm{~cm}$ due to difficulties with the insertion. Repeated reduction of the prolapsed rectum was attempted without success. The histology report of the rectal biopsy indicated an adenomatous lesion with severe dysplasia.

The patient was subsequently prepared for surgical intervention for the rectal prolapse. However, she developed signs of sepsis with tachycardia and a raised white blood cell count five days after admission. Computed tomography (CT) of the abdomen and pelvis was performed on clinical suspicion of an abdominal cause for the sepsis. The result showed a rectosigmoid junction intussusception with a lead point distal to the anal canal. This was associated with proximal bowel dilation suggestive of intestinal obstruction with a distended caecum (Fig. 3a \& b).

An emergency open laparotomy was performed. Intraoperatively, we found a large long-segment sigmoid intussusception (Fig. 4), with a large distal sigmoid polyp as the leading point. It resulted in a prolapse of the intussusceptum through the anus, thus mimicking a rectal prolapse. Manual reduction of the intussusceptum transabdominally, aided by a perineal approach, was unsuccessful in view of the tight intussusceptum. We first dissected off the intussuscepted part of the sigmoid colon (Fig. 5) in an attempt to decompress the rest of the large bowel. However, this proved to be challenging and bowel decompression was performed through an enterotomy in the caecum. More than $1 \mathrm{~L}$ of stools and fluid was aspirated. A total colectomy and end ileostomy was performed in view of the unhealthy caecum, which was dilated with patchy areas of necrosis, and the ischaemic intussuscepted sigmoid colon (Fig. 5). An ileorectal anastomosis was not performed, as the patient was bedridden (which made perineal care and hygiene a challenge) and her anal sphincters were assessed intraoperatively to be lax.

Postoperatively, the patient was managed in a surgical high-dependency unit. She developed postoperative ileus and atrial flutter, which were responsive to medical treatment. Total parenteral nutrition was started and the patient progressed to nasogastric tube feeding on postoperative day (POD) 5. She

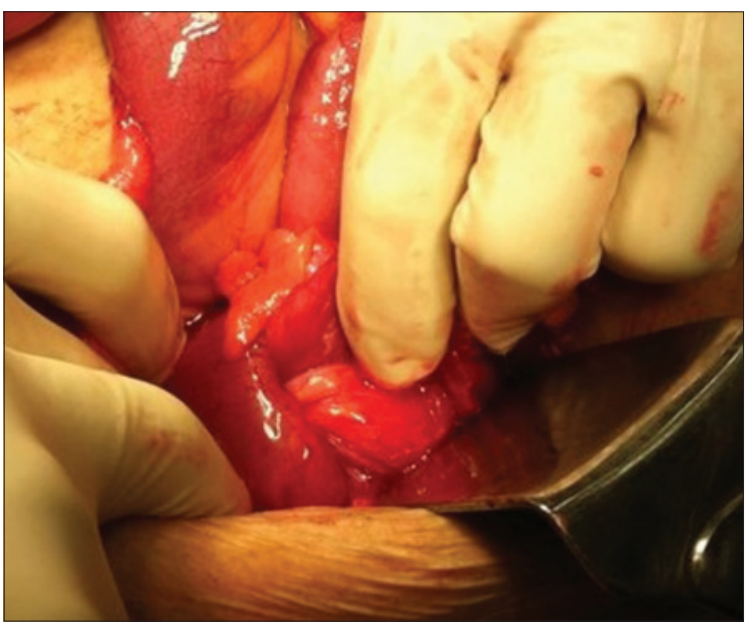

Fig. 4 Intraoperative photograph shows sigmoid intussusception.

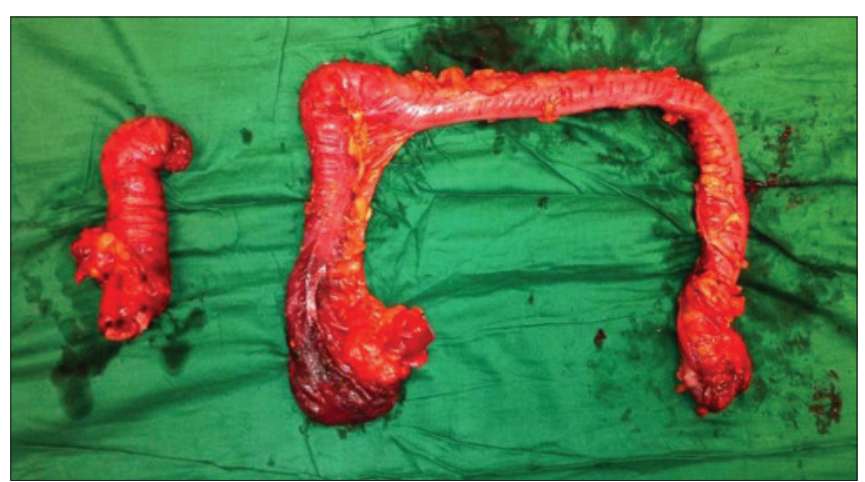

Fig. 5 Photograph shows sample from the sigmoid intussusception (left) and colon with caecum necrosis (right) following total colectomy.

was transferred to the general ward on POD 6. Due to mild dysphagia secondary to postoperative deconditioning, the patient was discharged with nasogastric tube feeding on POD 17. The final histology of the polyp was that of a partially necrotic polyp, tubulovillous adenoma, with high grade dysplasia. A focus on the base of the polyp raised the suspicion of submucosal invasion.

\section{DISCUSSION}

Intussusception in adults is relatively rare and presentations are not typical, compared with the triad of symptoms described in paediatric cases (abdominal pain, mass and PR bleeding). In a retrospective review of 41 intussusception cases, 95.1\% (39/41) 
Table I. Similar case reports of intussusception presenting as rectal prolapse published in the last $\mathbf{3 0}$ years.

\begin{tabular}{|c|c|c|c|c|c|c|c|}
\hline $\begin{array}{l}\text { Year of } \\
\text { publication }\end{array}$ & $\begin{array}{l}\text { Age of } \\
\text { patient }\end{array}$ & $\begin{array}{l}\text { Symptoms and } \\
\text { duration }\end{array}$ & $\begin{array}{l}\text { Length of } \\
\text { prolapse } \\
(\mathrm{cm})\end{array}$ & $\begin{array}{l}\text { Pathological } \\
\text { cause }\end{array}$ & $\begin{array}{l}\text { Intussusception } \\
\text { sites }\end{array}$ & Indication for surgery & Procedure performed \\
\hline $1988^{(3)}$ & $4 \mathrm{yr}$ & $\begin{array}{l}\text { Prolapsed rectal } \\
\text { mass }\end{array}$ & 4 & $\begin{array}{l}\text { Burkitt's } \\
\text { lymphoma }\end{array}$ & Cecoanal & $\begin{array}{l}\text { lleocecal opening visible, } \\
\text { diagnosis of intussusception } \\
\text { made }\end{array}$ & $\begin{array}{l}\text { Partial resection of } \\
\text { caecum and reduction } \\
\text { of intussusception }\end{array}$ \\
\hline $1998^{(4)}$ & $46 \mathrm{yr}$ & $\begin{array}{l}\text { Acute onset of } \\
\text { rectal prolapse }\end{array}$ & 10 & $\begin{array}{l}\text { Large } \\
\text { sigmoid } \\
\text { lipoma }\end{array}$ & Sigmoid & $\begin{array}{l}\text { Diagnosis of intussusception } \\
\text { made by colonoscopy and } \\
\text { ischaemic bowel }\end{array}$ & $\begin{array}{l}\text { Sigmoid colon resection, } \\
\text { primary anastomosis } \\
\text { and rectopexy }\end{array}$ \\
\hline $2005^{(5)}$ & $3 \mathrm{yr}$ & $\begin{array}{l}\text { Large prolapsed } \\
\text { mass from anus }\end{array}$ & 15 & None & $\begin{array}{l}\text { Ileal invagination } \\
\text { and sigmoidorectal } \\
\text { intussusception }\end{array}$ & $\begin{array}{l}\text { Ischaemic changes of the } \\
\text { prolapsed part }\end{array}$ & $\begin{array}{l}\text { Ischaemic bowel } \\
\text { resection and sigmoid } \\
\text { colostomy }\end{array}$ \\
\hline $2007^{(6)}$ & $10 w k$ & $\begin{array}{l}\text { Prolapsed rectal } \\
\text { mass }\end{array}$ & $6-8$ & None & Ileocolic & None & $\begin{array}{l}\text { Fluoroscopic-guided } \\
\text { pneumatic reduction }\end{array}$ \\
\hline $2008^{(8)}$ & $36 \mathrm{yr}$ & $\begin{array}{l}\text { Prolapsed } \\
\text { rectal mass and } \\
\text { abdominal pain }\end{array}$ & NA & $\begin{array}{l}\text { Large } \\
\text { submucosal } \\
\text { lipoma }\end{array}$ & Ileosigmoid & $\begin{array}{l}\text { Worsening pain after first } \\
\text { surgical reduction of 'rectal } \\
\text { prolapse' }\end{array}$ & $\begin{array}{l}\text { Surgical reduction of } \\
\text { 'rectal prolapse' and } \\
\text { subtotal colectomy }\end{array}$ \\
\hline $2011^{(9)}$ & $52 \mathrm{yr}$ & $\begin{array}{l}\text { Large mass } \\
\text { protruding from } \\
\text { anus }\end{array}$ & 12 & None & Sigmoid & $\begin{array}{l}\text { Diagnosis of intussusception } \\
\text { and ischaemic changes of } \\
\text { prolapsed part }\end{array}$ & Hartmann's procedure \\
\hline $2011^{(10)}$ & $66 \mathrm{yr}$ & $\begin{array}{l}\text { Large mass } \\
\text { protruding from } \\
\text { anus }\end{array}$ & $>10$ & None & Sigmoid & $\begin{array}{l}\text { Diagnosis of intussusception } \\
\text { and gangrenous prolapsed } \\
\text { part }\end{array}$ & Hartmann's procedure \\
\hline
\end{tabular}

NA: not applicable

had abdominal pain, 26.8\% (11/41) had bloody stool and 34.1\% $(14 / 41)$ had a palpable abdominal mass. However, the classic triad presentation was only seen in $9.8 \%(4 / 41)$ of the adult patients in the study. ${ }^{(2)}$ Most adult intussusception patients present with chronic, intermittent and nonspecific symptoms, making accurate diagnosis relatively difficult. As a result, the majority of diagnoses are delayed, missed or only made during surgery. In our case, the patient appeared to have rectal prolapse, an even rarer presentation for intussusceptions.

In Table I, we summarise similar case reports that were published in the last 30 years. All the cases presented with rectal prolapse, which turned out to be the result of intussusception.

When differentiating between intussusceptions and rectal prolapse, physicians need to take note of the following three areas: patient history; physical examination; and further investigations.

Although intussusceptions through the anus and rectal prolapse share some common features in the patient's medical history (such as chronic constipation), patients with intussusception usually have chronic abdominal pain associated with distension. Some patients can have chronic obstructive symptoms such as nausea or vomiting, and others can develop symptoms of malignancy such as weight loss and abdominal mass. However, some symptoms might be more suggestive of the diagnosis of intussusception. Dvorkin et al compared the symptoms of 377 patients with either rectal intussusception or rectocele with their proctography results. They found that the symptoms of anorectal pain and prolapse were highly predictive of isolated intussusception, as compared with rectocele.
The symptom of 'toilet revisiting' was also more closely associated with the finding of rectoanal intussusception. ${ }^{(11)}$

During physical examination, firstly, it is important to note that intussusceptions may have a leading point lesion on the protruding mass (as presented in our case), which does not occur in cases of rectal prolapse. Of the eight cases presented in Table I, intussusception had a pathological cause in four cases. Three of these four patients had intraluminal lesions, which all presented as the leading point of the protruding mass. Secondly, in the event of rectal prolapse, there should be continuity between perianal tissue and protruding tissue. However, in intussusception, there is a space between the protruding mucosa and anal wall. This can be detected by careful digital rectal examination. Furthermore, in the event of an intussusception, the patient could show abdominal signs such as distension, tenderness or abdominal mass.

Further investigations can help to identify intussusceptions. First, endoscopic investigations such as colonoscopy and sigmoidoscopy play an important role in evaluating the underlying causes (leading point) of intussusceptions and obtaining a histology sample, which will help in planning further treatments. ${ }^{(12)}$ Second, CT of the abdomen and pelvis is one of the most useful and accurate methods to identify intussusceptions. ${ }^{(13,14)}$ It can provide sufficient information about the site of the intussusception, its extent, underlying lesion, dilatation of bowel, signs of obstruction and most importantly, whether it is noninvasive.

For early definitive management, prompt diagnosis and differentiation between a rectal prolapse and a large transanal 
intussuception is crucial, especially for severely ill patients with a lesion as a leading point. Diagnoses should be built on careful history-taking, physical examination and relevant investigations. An early CT of the abdomen and pelvis may be helpful if intussusception is of diagnostic concern.

\section{REFERENCES}

1. Yakan S, Caliskan C, Makay O, Denecli AG, Korkut MA. Intussusception in adults: clinical characteristics, diagnosis and operative strategies. World J Gastroenterol 2009; 15:1985-9.

2. Wang N, Cui XY, Liu Y, et al. Adult intussusception: a retrospective review of 41 cases. World J Gastroenterol 2009; 15:3303-8.

3. Greif F, Burstein Y, Hammer B. Burkitt's lymphoma protruding through the anus. Report of an unusual case. Dis Colon Rectum 1988; 31:629-31.

4. Younes ZH, Johnson DA, Dimick L. Sigmoido-anal intussusception presenting as rectal prolapse: role of endoscopic diagnosis. Gastrointest Endosc 1998; 47:561-3.

5. Abantanga FA. Ileal invagination of the sigmoid colon producing a sigmoidorectal intussusception combined with rectal prolapse in a 3-yearold child. Pediatr Surg Int 2005; 21:400-2.

6. Tennant $\mathrm{S}$, Halliday K. Intussusception mimicking rectal prolapse. Pediatr Radiol 2008; 38:700-2.

7. Chen CW, Hsiao CW, Wu CC, et al. Rectal prolapse as initial clinical manifestation of colon cancer. Z Gastroenterol 2008; 46:348-50.

8. Chen $\mathrm{R}$, Zhao $\mathrm{H}$, Sang $X$, et al. Severe adult ileosigmoid intussusception prolapsing from the rectum: A case report. Cases J 2008; 1:198.

9. Roy J, Gouda M, Reddy BS, Baker RP. Sigmoid intussusception presenting as rectal prolapse in an adult. Colorectal Dis 2011; 13:e385.

10. Teyha PS, Chandika A, Kotecha VR. Prolapsed sigmoid intussusception per anus in an elderly man: a case report. J Med Case Rep 2011; 5:389.

11. Dvorkin LS, Knowles CH, Scott SM, et al. Rectal intussusception: characterization of symptomatology. Dis Colon Rectum 2005; 48:824-31.

12. Marinis A, Yiallourou A, Samanides L, et al. Intussusception of the bowel in adults: a review. World J Gastroenterol 2009; 15:407-11.

13. Takeuchi K, Tsuzuki Y, Ando T, et al. The diagnosis and treatment of adult intussusception. J Clin Gastroenterol 2003; 36:18-21.

14. Tan KY, Tan SM, Tan AG, et al. Adult intussusception: experience in Singapore. ANZ J Surg 2003; 73:1044-7. 